\title{
Interplay Between Notch and YAP/TAZ Pathways in the Regulation of Cell Fate During Embryo Development
}

\section{OPEN ACCESS}

Edited by: Andrea Erika Münsterberg, University of East Anglia, United Kingdom

Reviewed by:

Sirio Dupont,

University of Padua, Italy Jordi Cayuso,

University of Wolverhampton, United Kingdom

${ }^{*}$ Correspondence: Cristina Pujades

cristina.pujades@upf.edu orcid.org/0000-0001-6423-7451

Specialty section:

This article was submitted to Morphogenesis and Patterning, a section of the journal Frontiers in Cell and Developmental Biology

Received: 18 May 2021 Accepted: 02 August 2021

Published: 19 August 2021

Citation: Engel-Pizcueta $C$ and Pujades $C$ (2021) Interplay Between Notch and YAP/TAZ Pathways in the Regulation of Cell Fate During Embryo Development. Front. Cell Dev. Biol. 9:711531. doi: 10.3389/fcell.2021.711531

\section{Carolyn Engel-Pizcueta and Cristina Pujades* \\ Department of Experimental and Health Sciences, Universitat Pompeu Fabra, Barcelona, Spain}

Cells in growing tissues receive both biochemical and physical cues from their microenvironment. Growing evidence has shown that mechanical signals are fundamental regulators of cell behavior. However, how physical properties of the microenvironment are transduced into critical cell behaviors, such as proliferation, progenitor maintenance, or differentiation during development, is still poorly understood. The transcriptional co-activators YAP/TAZ shuttle between the cytoplasm and the nucleus in response to multiple inputs and have emerged as important regulators of tissue growth and regeneration. YAP/TAZ sense and transduce physical cues, such as those from the extracellular matrix or the actomyosin cytoskeleton, to regulate gene expression, thus allowing them to function as gatekeepers of progenitor behavior in several developmental contexts. The Notch pathway is a key signaling pathway that controls binary cell fate decisions through cell-cell communication in a contextdependent manner. Recent reports now suggest that the crosstalk between these two pathways is critical for maintaining the balance between progenitor maintenance and cell differentiation in different tissues. How this crosstalk integrates with morphogenesis and changes in tissue architecture during development is still an open question. Here, we discuss how progenitor cell proliferation, specification, and differentiation are coordinated with morphogenesis to construct a functional organ. We will pay special attention to the interplay between YAP/TAZ and Notch signaling pathways in determining cell fate decisions and discuss whether this represents a general mechanism of regulating cell fate during development. We will focus on research carried out in vertebrate embryos that demonstrate the important roles of mechanical cues in stem cell biology and discuss future challenges.

Keywords: YAP/TAZ pathway, Notch signaling pathway, cell fate, embryonic development, mechanical cues

\section{CELL AND TISSUE MECHANICS DURING EMBRYONIC DEVELOPMENT}

How is a functional multiorgan system generated from a single, pluripotent cell? This fascinating question was already a major focus in $\mathrm{D}^{\prime}$ Arcy Thompson's book On Growth and Form (Thompson, 1917), in which he discussed the mechanisms by which organisms acquire their final sizes and shapes through growth. The understanding of how cell fate specification and proliferation are 
coordinated with tissue morphogenesis is crucial for unveiling the mechanisms underlying both normal and pathological tissue growth. Although classical developmental studies have been mainly focused on the role of biochemical signals, mechanical forces also play an important role in coordinating cell behavior with tissue morphogenesis (reviewed in Heer and Martin, 2017; Kumar et al., 2017; Labernadie and Trepat, 2018). Cells in developing tissues sense mechanical forces through cellextracellular matrix (ECM) and cell-cell contacts, which are transmitted within and between cells through the cytoskeleton and adhesion molecules. Most of the current work in the mechanobiology field is devoted to the understanding of how forces drive the arrangement of cells in space such as cell intercalation, cell migration, or collective cell migration during self-organization and spreading of tissues. From those studies we know how forces produced by oriented cell division and growth, directed cell crawling or bending of cell sheets, integrate local cell shape changes (for reviews see Heisenberg and Bellaïche, 2013; Collinet and Lecuit, 2021). However, how such mechanical forces influence cell fate is still an open question. The molecular mechanisms driven by mechanical forces that control cell behaviors are partially understood. Nevertheless, we still do not have a comprehensive view of how the molecular mechanisms within cells are converted to mechanical forces during development. While the role of mechanical forces in cell fate can be studied in stem cell cultures, in vitro approaches do not provide insight into morphogenesis. Thus, understanding how mechanical signals control specific cell behaviors during morphogenesis is key to shedding light on how an organism is generated.

In this review, we will address the roles that mechanical cues have in binary cell fate decisions in different vertebrate developing tissues. Due to the increasing literature in the very last years and space limitations, we will cover a subset of representative studies in the field. Specifically, we will focus on the interplay between the highly conserved YAP/TAZ and Notch pathways. We will highlight the main findings of the recent research and discuss some of the unknowns in the field.

\section{THE USUAL SUSPECTS: YAP/TAZ-TEAD AS SENSORS AND TRANSDUCERS OF MECHANICAL CHANGES}

\section{The Core of YAP/TAZ-TEAD}

In the last few years, studies have started to disentangle how mechanical signals are interpreted by cells during morphogenesis, and how this results in specific cell behaviors. In this section, we will focus on the role of YAP/TAZ in this process.

The transcriptional co-activators Yes-associated protein (YAP) and its paralog TAZ (transcriptional co-activator with a PDZ binding domain; encoded by the wwtrl gene) are important regulators of tissue growth and regeneration (as reviewed in Hansen et al., 2015). YAP and TAZ regulation is best understood under the scope of the Hippo kinase cascade (Lei et al., 2008; Zhao et al., 2008). The Hippo pathway was initially identified through mosaic genetic screens for suppressors of tissue overgrowth in Drosophila melanogaster (Udan et al., 2003). Importantly, Hippo signaling cascade controls organ size and tissue homeostasis through the regulation of cell proliferation, apoptosis, and tissue regeneration (see review Zheng and Pan, 2019). Not surprisingly, deregulation of the pathway has been implicated in varieties of cancers and diseases (Plouffe et al., 2015). The core components of the Hippo pathway, the kinase Hippo (Hpo, or MST1 and MST2 in vertebrates), the kinase Warts (Wts, or LATS1 and LATS2 in vertebrates), and the effector Yorkie (Yki, or YAP and TAZ in vertebrates) are highly conserved from Drosophila to mammals (Hilman and Gat, 2011; Sebé-Pedrós et al., 2012). Despite the conservation of the core players, the upstream regulators of the pathway seem to be divergent (Hansen et al., 2015).

Activation of the Hippo kinase cascade results in the phosphorylation of Yki/YAP/TAZ, which inhibits their nuclear import. The upstream kinases of the cascade (Hippo or MST1/2) form a complex with the adaptor protein Salvador (SAV1 in vertebrates) that activates LATS1/2 kinases. LATS1/2 together with MATS/MOB1 phosphorylate and inactivate Yki (YAP and TAZ in vertebrates) by cytoplasmic retention and eventually ubiquitination and degradation (as reviewed in Panciera et al., 2017; Zheng and Pan, 2019). On the other hand, when Hippo is inactive, dephosphorylated YAP/TAZ can translocate into the nucleus and bind to the TEAD(1-4) transcription factors (Lei et al., 2008; Zhao et al., 2008). The YAP/TAZ-TEAD complex activates the expression of target genes that regulate cell proliferation, differentiation, and apoptosis (Dong et al., 2007; Lei et al., 2008; Zhao et al., 2008; Lian et al., 2010; Lee and Yonehara, 2012). Specifically, the YAP-TEAD complex controls gene transcription by mostly binding to distal enhancers (Galli et al., 2015). YAP/TAZ mainly act as co-activators but can also act as co-repressors together with TEAD factors (Beyer et al., 2013; Kim et al., 2015). Moreover, YAP/TAZ can bind to other transcription factors either with or without TEAD (as reviewed in Totaro et al., 2018b). Overall, although YAP/TAZ are the main known mediators of the Hippo pathway during development, YAP/TAZ-activity can be regulated by multiple microenvironmental cues beyond the Hippo pathway.

\section{YAP and TAZ as Mechanotransducers}

In the last years, YAP/TAZ have emerged as sensors of mechanical forces (Dupont et al., 2011; Panciera et al., 2017). YAP/TAZ mechanotransduction can be triggered by cell density either by cell-cell adhesion (see below), or reduced cell area (Aragona et al., 2013; Benham-Pyle et al., 2015)-, ECM rigidity (Dupont et al., 2011; Aragona et al., 2013; Elosegui-Artola et al., 2016), and shear stress (Nakajima et al., 2017). This regulation can be dependent or independently of the Hippo pathway. Within the cell density context, cell junction proteins regulate YAP/TAZ activity. For instance, Neurofibromatosis type 2 (NF2) works as a scaffold of the Hippo cascade components in cell-cell junctions. NF2 recruits LATS1/2 to the plasma membrane, enabling LATS1/2 activation by MTS1/2, which leads to inhibition of YAP/TAZ activity (Yin et al., 2013). Focal adhesions components, which contact the cell at the adjacent 
ECM, also regulate YAP/TAZ activity by modulating YAP subcellular location (Kim and Gumbiner, 2015; Elosegui-Artola et al., 2016). ECM stiffness and cell geometry control YAP/TAZ activity through small RhoGTPases triggering the actomyosin cytoskeleton tension in a Hippo independent manner (Dupont et al., 2011). Accordingly, F-actin inhibitor proteins mediate the spatial distribution of YAP/TAZ activity by mechanical forces along the tissue (Aragona et al., 2013). Forces exerted from the ECM can drive YAP/TAZ activity through different mechanisms. The Ras-related GTPase RAP2 transduces ECM stiffness into YAP/TAZ cellular responses through the activation of the Hippo pathway (Meng et al., 2018). The nuclear SWI/SNF complex inhibits YAP/TAZ as a response to mechanical signaling, in such a manner that to trigger YAP/TAZ activity, both YAP/TAZ nuclear accumulation and SWI/SNF inhibition are required (Chang et al., 2018). ECM forces can regulate the transport through the nuclear pores driving YAP nuclear import in a Hippo independent manner (Elosegui-Artola et al., 2017). Moreover, Piezo1, a mechanosensitive ion channel, can mediate the effects of substrate stiffness on YAP nuclear location (Pathak et al., 2014). Remarkably, YAP/TAZ are not only modulated by mechanical forces but can contribute to changes in actomyosin-mediated mechanical forces in cell culture and in developing tissues by regulating the expression of cytoskeletal and ECM genes (Porazinski et al., 2015; Lin et al., 2017; Nardone et al., 2017). Furthermore, biochemical cues also control YAP/TAZ activity (for recent reviews see Pocaterra et al., 2020; Heng et al., 2021). Extracellular cues can activate or inhibit YAP/TAZ activity through G-protein-coupled receptors (GPCRs). RhoGTPases mediate YAP/TAZ activation by GPCRs, modulating actomyosin cytoskeleton tension (Yu et al., 2012). Altogether, YAP/TAZ act as core integrators of chemical and mechanical cues in different biological contexts.

\section{YAP/TAZ in the Control of Cell Proliferation During Development}

YAP/TAZ function as gatekeepers of progenitor cell behavior in several contexts during embryonic development. Specifically, YAP/TAZ have mainly been described as regulators of cell proliferation and tissue growth (Camargo et al., 2007; Lei et al., 2008; Ota and Sasaki, 2008). YAP/TAZ trigger proliferation of gastrointestinal mesenchymal progenitors (Cotton et al., 2017) and cranial neural crest cells (Wang et al., 2016). YAP by itself also controls the proliferation of cardiomyocytes (Heallen et al., 2011) and lung epithelial cells (Lin et al., 2017). Moreover, YAPTEAD maintains inner ear progenitors through the activation of cell cycle and stemness genes (Gnedeva et al., 2020). In the same line, YAP/TAZ regulate cell proliferation in neural progenitors in the chick spinal cord by controlling their stemness properties through the activation of the cell cycle regulator cyclinD1 and the inhibition of the neural differentiation marker NeuroM (Cao et al., 2008). YAP/TAZ-TEAD signaling also regulates the proliferation of neural progenitors in the mammalian embryonic brain (Han et al., 2015). YAP/TAZ drive the expansion of neural progenitors in the hippocampus downstream of NF2 (Lavado et al., 2013) and maintain neural progenitors in the developing cortex by activating the transcription of proliferation genes and preventing neural differentiation (Lavado et al., 2018). Along this, YAP also maintains the proliferative properties of basal progenitors in the developing ferret and human cortex (Kostic et al., 2019). Finally, YAP/TAZ-TEAD drives proliferation of neural progenitors in the zebrafish hindbrain boundaries downstream of actomyosin tension (Voltes et al., 2019). Although YAP/TAZ play essential roles in tissue growth during embryonic development, they are not required for normal physiology in most of adult tissues. Thus, while YAP/TAZ overexpression have a widely effect driving tissue hyper-proliferation and promoting tissue repair after injury, the deletion of YAP/TAZ in many adult contexts does not result in effects on tissue proliferation. Overall, YAP/TAZ play a crucial role in the self-renewal of progenitor cells during embryonic development.

\section{THE NOTCH PATHWAY AS THE KEY REGULATOR OF BINARY CELL FATE DECISIONS IN DEVELOPMENT}

\section{Binary Cell Fate Decisions Through Cell-Cell Communication}

The Notch signaling pathway is the main regulator of binary cell fate decisions during embryonic development (ArtavanisTsakonas et al., 1999). Notch signaling operates through cell-cell communication, with one cell displaying the Notch receptor and its neighboring cell the Notch ligand. Nevertheless, Notch receptors and ligands can also form cis interactions that inhibit (de Celis and Bray, 1997; Micchelli et al., 1997) or activate (Nandagopal et al., 2019) Notch signaling in a cell-autonomous manner. The Notch pathway is highly conserved in metazoan species (Gazave et al., 2009). In mammals, there are four Notch receptors (Notch1-4) and five ligands: three Delta ligands (Dll1, Dll3, and Dll4) and two Jagged ligands (Jag1 and Jag2). Upon ligand binding (Delta or Jagged) in its extracellular domain, the Notch receptor undergoes several protease cleavages, thereby releasing the Notch Intracellular Domain (NICD), which then translocates into the nucleus. Once there, the NICD forms a complex with the transcription factor RBPJ (Recombination signal-Binding Protein for Ig Kappa J region) and recruits co-activators such as MAML (Mastermind-Like). The NICDRBPJ complex activates transcription of the main effectors of the pathway, the transcriptional repressors genes Enhancer of Split (Espl) in Drosophila and Hes/Her in vertebrates. The Hes/Her transcription factors repress genes driving cell specification (e.g., proneural genes), cell differentiation, and cell cycle arrest (reviewed in Kageyama et al., 2007). Hes/Her can also repress - directly or indirectly - Notch ligand expression. Through this lateral inhibition mechanism, one cell is singled out from an equipotent field to acquire a specific fate, repressing this specific fate in the neighboring cells (reviewed in Henrique and Schweisguth, 2019).

However, the lateral inhibition paradigm should not only be viewed from a static perspective. Some of the Notch effectors, such as Hes 1 and Hes7, show an oscillatory expression by 
a negative autoregulatory loop in different developing tissues (Hirata et al., 2002; Bessho et al., 2003; Lahmann et al., 2019; Seymour et al., 2020), resulting in the oscillation of their targets (Masamizu et al., 2006; Shimojo et al., 2008; Lahmann et al., 2019). The oscillation of Hes genes and their targets keep progenitors in an undifferentiated and proliferative state, whereas the sustained expression of one of the target genes drives cell specification (Shimojo et al., 2008; Lahmann et al., 2019). Overall, Hes oscillations constitute a crucial mechanism in the control of binary cell fate decisions during embryonic development.

Moreover, Notch not only controls cell fate through lateral inhibition, but also through lateral induction (de Celis and Bray, 1997). Lateral induction consists of a positive feedback loop in which Notch signaling activates the expression of the Notch ligand, thereby activating Notch signaling in the adjacent cell. Subsequently, both interacting cells acquire the same fate. For instance, Jag1-Notch signaling through lateral induction drives prosensory fate in the developing inner ear (Hartman et al., 2010) and vascular smooth muscle fate in neural crest cells (Manderfield et al., 2012). This highlights another level of complexity in the control of cell fate decisions by Notch signaling in the developing embryo.

\section{Context Dependency of Notch Control of Cell Fate Decisions}

The role of the Notch pathway during development is highly context dependent (Bray, 2016). In vertebrates, different combinations and spatiotemporal expression of Notch receptors and ligands account for part of this context dependency. For example, the control of neuronal fates in the zebrafish spinal cord relies on different combinations of Notch ligands and receptors (Okigawa et al., 2014). Different ligands can also trigger distinct responses through the same Notch receptor. For instance, Jagged and Delta ligands drive different outcomes in the control of cell fate decisions during inner ear development and angiogenesis (Benedito et al., 2009; Petrovic et al., 2014). Likewise, Dll1 and Dll4 induce different Notch activation dynamics, driving different gene programs and cell fates (Nandagopal et al., 2018). Additionally, Fringe glycotransferases modify the affinity between Notch receptors and ligands (Panin et al., 1997), providing an extra regulatory layer. Epigenetic mechanisms may explain part of the Notch context dependency. For example, epigenetic modifications in the regulatory regions of Notch targets regulate cell fate decisions in olfactory and cortical neurogenesis (Endo et al., 2011; Tiberi et al., 2012). Moreover, the NICD-RBPJ complex can interact with other transcription factors (reviewed in Bray, 2016). Hence, the interplay between Notch signaling and other pathways is relevant for the diversity of Notch responses. Cell geometry is also crucial for Notch regulation of cell fate during development (Shaya et al., 2017). All this complexity raises the question of how the interactions between Notch signaling, the microenvironment and other signaling pathways contribute to Notch pleiotropic effects during development.

\section{MECHANOSENSING IN THE CONTROL OF CELL FATE DECISIONS}

Notch controls binary cell fate decisions during morphogenesis, while YAP/TAZ transduce physical properties of the microenvironment into critical cell decisions. In this chapter, we will discuss the different described biological roles of Notch and $\mathrm{YAP} / \mathrm{TAZ}$, and their interplay in the control of binary cell fates in several contexts.

YAP/TAZ regulate cell fate in response to mechanical signals in different tissues. In the preimplantation embryo, YAP/TAZTEAD promote the specification of the trophectoderm fate (Nishioka et al., 2009). In the nervous system, YAP controls neocortical astrocyte (Huang et al., 2016) and retinal pigment epithelium fate (Miesfeld et al., 2015; Kim et al., 2016). In the kidney, YAP drives nephron differentiation downstream of the small RhoGTPase Cdc42 (Reginensi et al., 2013). YAPTEAD also regulates the program of airway epithelial progenitor specification (Mahoney et al., 2014) and the hematopoietic stem cell fate in response to cyclic stretch (Lundin et al., 2020). Furthermore, YAP/TAZ inhibit smooth muscle cell differentiation in the developing gut (Cotton et al., 2017) and control the formation of the signaling center, the enamel knot, during tooth development (Li et al., 2016). TAZ (without YAP) also controls cell specification such as micropyle precursor cell fate during zebrafish oogenesis (Dingare et al., 2018). Specifically, TAZ activity singles out this micropyle precursor cell through a lateral inhibition mechanism based on differential cell growth, generating pushing forces that exclude nuclear TAZ in the neighboring cells (Xia et al., 2019). This mechanism challenges the classic paradigm of lateral inhibition being an exclusively Notch-Delta mechanism to singularize cells from an equipotent cell field. Altogether, YAP/TAZ act as integrators of mechanical inputs, regulating the balance between progenitor and differentiated cells in different developmental contexts.

Moreover, Notch has also been proposed to be a sensor of the microenvironment (reviewed in Lloyd-Lewis et al., 2019; Stassen et al., 2020). At the molecular level, pulling forces from the sending cell can activate Notch1 signaling (Gordon et al., 2015; Chowdhury et al., 2016). The main examples of this have been described in the vascular system. In adult arteries, Notch1 works as a mechanosensor downstream of shear stress, controlling arterial identity and proliferation in endothelial cells (Mack et al., 2017). Similarly, the Notch3-Jag1 complex senses mechanical cues, potentially regulating the behavior of vascular smooth muscle cells (Loerakker et al., 2018). However, Notch1 is necessary but not sufficient to transduce the shear stress generated by the onset of blood flow in mouse embryos (Jahnsen et al., 2015). Hence, Notch is involved in the regulation of these processes in collaboration with other mechanosensors. Along this line, endothelial Piezol triggers a Notch1 response to mechanical signals by activating the metalloprotease responsible for the Notch receptor intracellular cleavage (Caolo et al., 2020). Overall, these studies point to Notch as a putative sensor and transducer of mechanical forces. Whether Notch controls cell fate during development downstream of mechanical forces 
alone or in collaboration with other mechanosensors remains an open question.

In recent years, the interplay between YAP/TAZ and Notch has been proposed to regulate a wide range of biological processes. In the next section, we will cover the crosstalk between YAP/TAZ-TEAD and Notch signaling as a key link between mechanical signals and binary cell fate decisions during embryonic development. Specifically, we will describe the different following modes of action proposed to date: (i) the cooperation between the Notch and YAP/TAZ pathways (Figure 1); (ii) YAP/TAZ acting upstream of Notch signaling (Figure 2); and (iii) Notch signaling acting upstream of YAP/TAZ (Figure 3).

\section{Cooperation Between the Notch and YAP/TAZ Pathways in Binary Cell Fate Decisions}

The first binary cell fate decision in the mammalian embryo occurs during the transition from morula to blastocyst, with the decision made between becoming trophectoderm (TE) or inner cell mass (ICM). YAP/TAZ-TEAD drive the specification of the TE fate downstream of cell polarity through Hippodependent and independent mechanisms (Nishioka et al., 2009; Cockburn et al., 2013; Hirate et al., 2013; Leung and ZernickaGoetz, 2013; Lorthongpanich et al., 2013). In the blastocyst, Notch is specifically activated in the outer cells, which will give rise to the TE. Notch and YAP-TEAD activate the expression of the TE specification gene, $C d x 2$, by binding to its TE-specific enhancer (Rayon et al., 2014). Moreover, the helicase-like protein Strawberry Notch1 (Sbno1) interacts with the YAP-TEAD and NICD-RBPJ complexes, operating as an integrator of these complexes in the activation of the TEenhancer of $C d x 2$ (Watanabe et al., 2017). This activation is not redundant since Notch regulates the onset of $C d x 2$ expression whereas YAP-TEAD maintains $C d x 2$ expression. Thus, through this mechanism, YAP-TEAD and Notch cooperate in the specification of the TE in a parallel and independent manner (Menchero et al., 2019). In vitro stretching of embryonic stem cells results in the activation of the TE enhancer of $C d x 2$ in the presence of YAP, TEAD, and Notch (Watanabe et al., 2017). Therefore, mechanical forces are upstream of the Notch and YAP-TEAD synergic mechanism in the binary cell fate decision between TE or ICM (Figures 1A,A').

The embryonic pancreas contains multipotent progenitors organized in tubular epithelial structures formed by a tip and a trunk domain. Bipotent pancreatic progenitors residing in the trunk domain give rise to the ductal and endocrine cells. The YAP-TEAD complex acts as a main regulator for the maintenance of human pancreatic progenitors by activating several targets, including Hes1 (Cebola et al., 2015). Further, YAP-TEAD forms a transcriptional complex with Hes1 that represses the expression of the endocrine specification gene, Neurog3. Importantly, mechanical signals regulate this cell fate decision both in vivo and in vitro: cell confinement drives endocrine specification whereas cell spreading triggers ductal specification. Accordingly, different ECM compositions define the lineage commitment of the mouse and human pancreatic progenitors. Pancreatic progenitors sensing fibronectin activate the YAP-TEAD-Hes 1 complex through the $\alpha 5$-integrin-F-actin axis, thereby repressing the endocrine cell fate. On the other hand, progenitors sensing laminin reduce the activation of the $\alpha 5$-integrin-YAP-Hes1 axis, committing to the endocrine fate (Mamidi et al., 2018). In this scenario, YAP-TEAD is upstream of Notch signaling meanwhile cooperating with Hes1 in the repression of Neurog3 expression to maintain pancreatic progenitors, which leads to the default commitment to the ductal lineage (Figures 1B,B').

YAP/TAZ forms a common transcriptional complex with the NICD in the control of smooth muscle differentiation from neural crest cells (Manderfield et al., 2015). Notch signaling plays a critical role in the differentiation of cardiac neural crest cells into smooth muscle cells through lateral induction (High et al., 2007). Firstly, the vascular endothelium displays a Jag1 ligand, which activates Notch signaling in the neighboring mesenchyme. Subsequently, Notch activates the smooth muscle differentiation program and Jag1 transcription, generating a positive feedback loop that controls smooth muscle differentiation (Manderfield et al., 2012). Specific deletion of YAP and TAZ in neural crest cells impairs smooth muscle differentiation. YAP/TAZ deletion decreases Jag1 and NICD expression in the mesenchyme, while NICD expression remains intact in endothelial cells. In this context, YAP physically interacts in a TEAD-independent manner with the NICD-RBPJ complex, activating Jag1 enhancer and the Hes 1 promoter in vivo and in vitro (Manderfield et al., 2015). This common YAP-NICD-RBPJ transcriptional complex contrasts with the parallel cooperation of YAP and NICD in the trophectoderm (Rayon et al., 2014; Watanabe et al., 2017; Menchero et al., 2019). In brief, Notch and YAP cooperate to activate the transcription of Notch targets controlling smooth muscle fate. Noteworthy, the vascular tissue is highly exposed to mechanical forces during development. Therefore, mechanical forces could be controlling smooth muscle fate through the regulation of YAP/TAZ and Notch.

\section{The YAP/TAZ Pathway Acting Upstream of Notch Signaling in Cell-Autonomous vs. Non-cell-Autonomous Mechanisms}

YAP/TAZ can act upstream of Notch signaling by activating Notch receptors. Notch participates in the binary decision between cholangiocytes and hepatocytes (Kodama et al., 2004; Zong et al., 2009). YAP controls the proliferation of hepatocytes and hepatic progenitors downstream of the Hippo pathway in the adult liver (Camargo et al., 2007; Zhou et al., 2009; Lee et al., 2010; Lu et al., 2010). In this context, YAP promotes the biliary cell fate downstream of NF2 regulation (Zhang et al., 2010). NF2 deficiency increases biliary precursors and cholangiocytes proliferation during development. Remarkably, Notch2 deficiency rescues this phenotype. In the absence of NF2, YAP activates Notch2 expression controlling biliary specification and cholangiocytes proliferation (Wu et al., 2017). Thus, YAP controls biliary cell fate and proliferation through the activation of the Notch 2 receptor during intrahepatic bile 


\section{COOPERATION BETWEEN NOTCH AND YAP/TAZ PATHWAYS}

Blastocyst

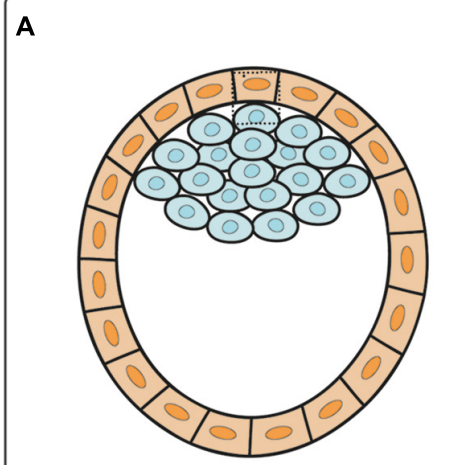

Trophectoderm vs. Inner Cell Mass

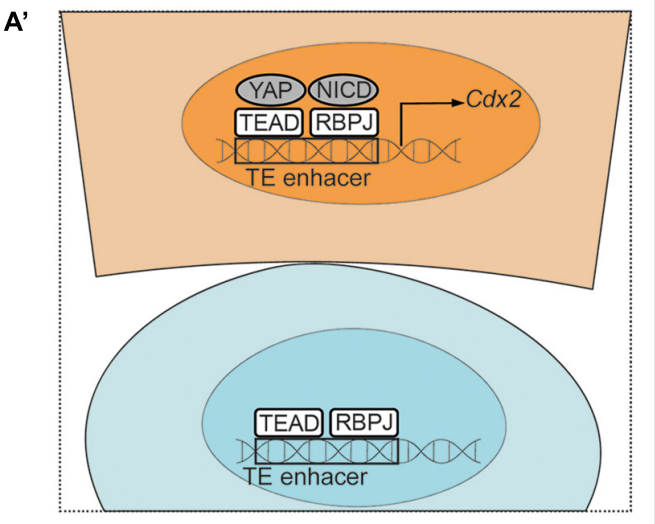

Embryonic pancreas

B

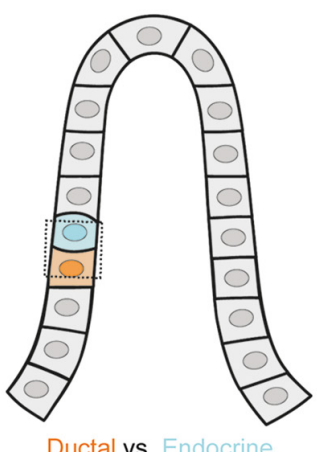

B'

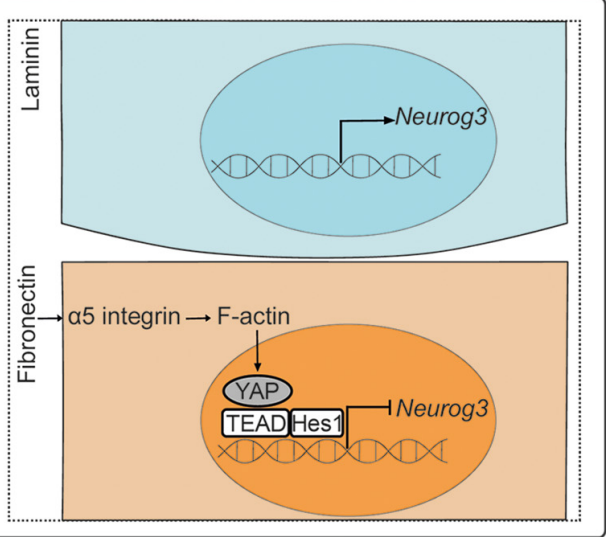

FIGURE 1 | Mechanosensing in the control of cell fate decisions: the cooperation between the Notch and YAP/TAZ pathways. (A,A') Schematic representation of a mouse blastocyst. Trophectoderm (TE) cells are depicted in orange and Inner Cell Mass (ICM) cells in blue. (A') Magnification of the framed region in (A). RBPJ and YAP-TEAD bind to the Cdx2 TE-enhancer and drive the TE fate (Rayon et al., 2014; Watanabe et al., 2017; Menchero et al., 2019). (B,B') Schematic representation of a mouse embryonic pancreas. Cells fated to the ductal linage are colored in orange and cells fated to the endocrine lineage in blue. Multipotent pancreatic progenitors are depicted in gray. (B') Magnification of the framed region in (B). The pancreatic progenitor cells sensing fibronectin activate the a5-integrin-F-actin-YAP axis. YAP-TEAD complex activates Hes 1 expression. Further, Hes1 binds to the YAP-TEAD complex repressing Neurog 3 expression and committing the progenitor cell to the ductal lineage (Mamidi et al., 2018).

duct development, as previously described in adult hepatocytes (Yimlamai et al., 2014). In the adult liver, YAP can also act upstream of Notch pathway by activating the expression of Jag1 (Tschaharganeh et al., 2013). In contrast, YAP/TAZ and Notch have been proposed to promote biliary cell fate through parallel mechanisms during development (Lee et al., 2016). Finally, YAP/TAZ and Notch control the binary decision between cholangiocytes and hepatocytes downstream of mechanical forces in the adult liver (Pocaterra et al., 2019, 2021). Whether this binary cell fate decision is controlled by YAP/TAZNotch downstream of mechanical forces during embryonic development is still unsolved.

On the other hand, YAP can inhibit Notch activity in a cell-autonomous manner, as it occurs during angiogenesis and somitogenesis. During embryonic angiogenesis, Notch controls the cell fate decision of tip vs. stalk cell. In tip cells, the
Notch ligand Dll4 triggers the formation of new sprouts and activates Notch in neighboring stalk cells, leading to tip fate suppression. Notch in stalk cells can also activate Dll4 expression, thus triggering Notch activation in tip cells (Caolo et al., 2010). This mechanism maintains arterial identity while regulating the formation of new branches. YAP/TAZ are activated in tip cells through the activation of the GPCRs, LPA4 and LPA6, mediated by actomyosin tension. YAP/TAZ control sprouting angiogenesis through the blockage of $\beta$ catenin-NICD mediated endothelial Dll4 expression. Altogether, YAP/TAZ inhibits Dll4 expression in tip cells in a cell-autonomous and TEAD-independent manner to control sprouting angiogenesis (Yasuda et al., 2019). In other words, as in smooth muscle differentiation, YAP/TAZ acts in a TEAD-independent manner in the regulation of Notch ligand expression. The second case is observed in the presomitic mesoderm (PSM) for the genetic synchronous oscillations of 


\section{YAP/TAZACTING UPSTREAM OF NOTCH SIGNALING}

\section{Fetal Muscle}

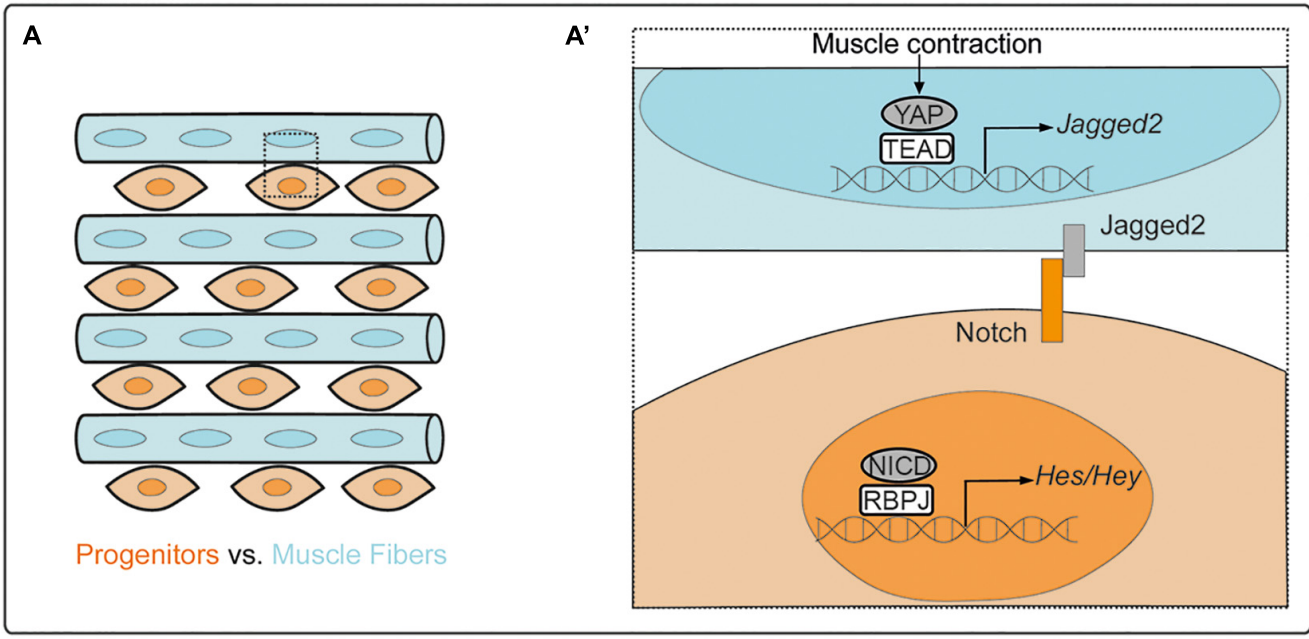

\section{Epidermis}

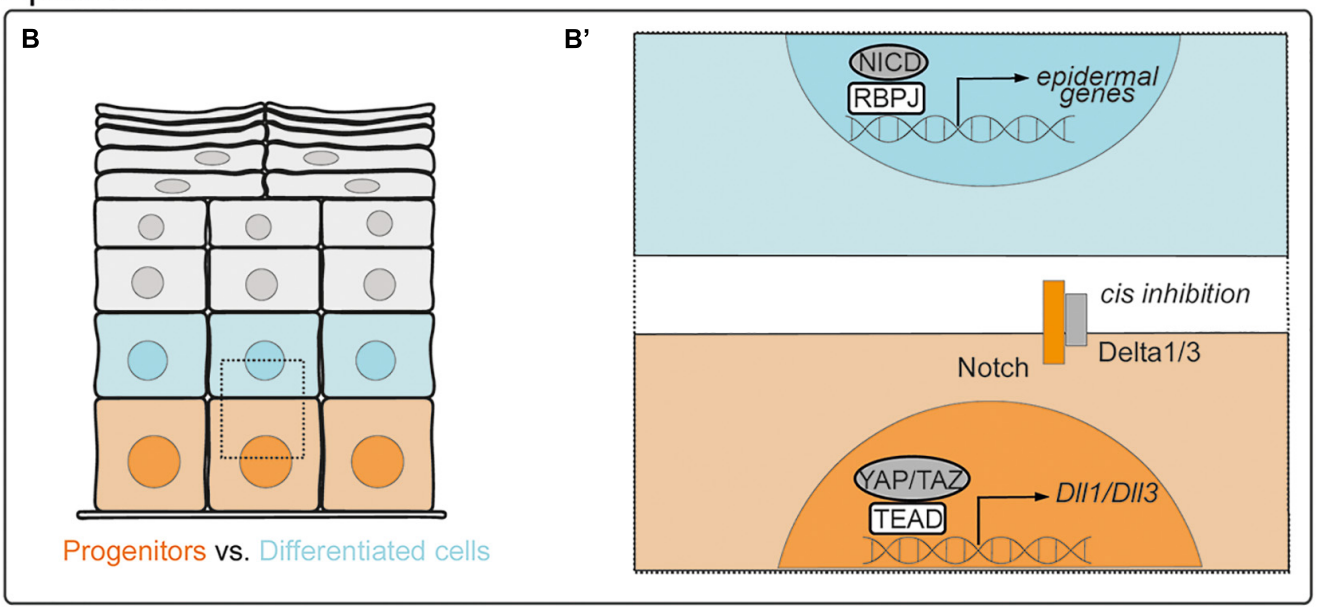

FIGURE 2 | Mechanosensing in the control of cell fate decisions: the YAP/TAZ pathway acting upstream of Notch signaling in cell-autonomous vs. non-cell-autonomous mechanisms. (A,A') Schematic representation of a chick fetal muscle. Muscle progenitors are depicted in orange and muscle fibers in blue. (A') Magnification of the framed region in (A). Upon muscle contraction, YAP translocates to the nucleus, binds to TEAD, and activates the transcription of Jag2. Jagged2 ligand activates Notch receptor in the neighboring cell and maintains the muscle progenitor in a non-cell-autonomous manner (Esteves de Lima et al., 2016). (B,B') Schematic representation of a mammalian epidermis. Epidermal progenitors are depicted in orange and cells committing to the epidermal fate in blue. Differentiated epidermal cells are depicted in gray. (B') Magnification of the framed region in (B). YAP/TAZ-TEAD drive the expression of D//1 and D//3 that cis inhibit Notch signaling in basal progenitors, preventing epidermal differentiation in a cell-autonomous manner (Totaro et al., 2017).

the Notch target Hes7 that precede the formation of somites, known as the segmentation clock. The segmentation clock has been proposed to be an excitable system (Hubaud et al., 2017). In this model, YAP activation provides an excitability threshold and Notch acts as the stimulus triggering the oscillations once it exceeds the threshold. Therefore, the collaboration of YAP and Notch is required for triggering and maintaining PSM oscillations. Importantly, YAP activation in the PSM cells is controlled by mechanical cues, such as cell density. In this scenario, Notch controls the decision between the quiescent and oscillatory state in PSM cells downstream of YAP activation by mechanical cues (Hubaud et al., 2017). In both contexts,
YAP inhibits Notch signaling to control cell behavior in a cellautonomous manner downstream of mechanical cues.

YAP can also be upstream Notch in a non-cell-autonomous manner. During fetal myogenesis, Notch controls the binary cell fate decision between muscle progenitors and differentiated muscle cells (Vasyutina et al., 2007). In the chick embryonic limb, nuclear YAP is expressed in differentiated muscle cells and in a subpopulation of muscle progenitors. YAP controls the maintenance but not proliferation of muscle progenitors downstream of muscle contraction. In muscle fibers, YAPTEAD binds to the Jag2 promoter and activates Jag2 expression. Consistently, Jag2 expression in muscle fibers as well as Notch 


\section{NOTCH SIGNALING UPSTREAM OF YAP/TAZ}

\section{Cortex}

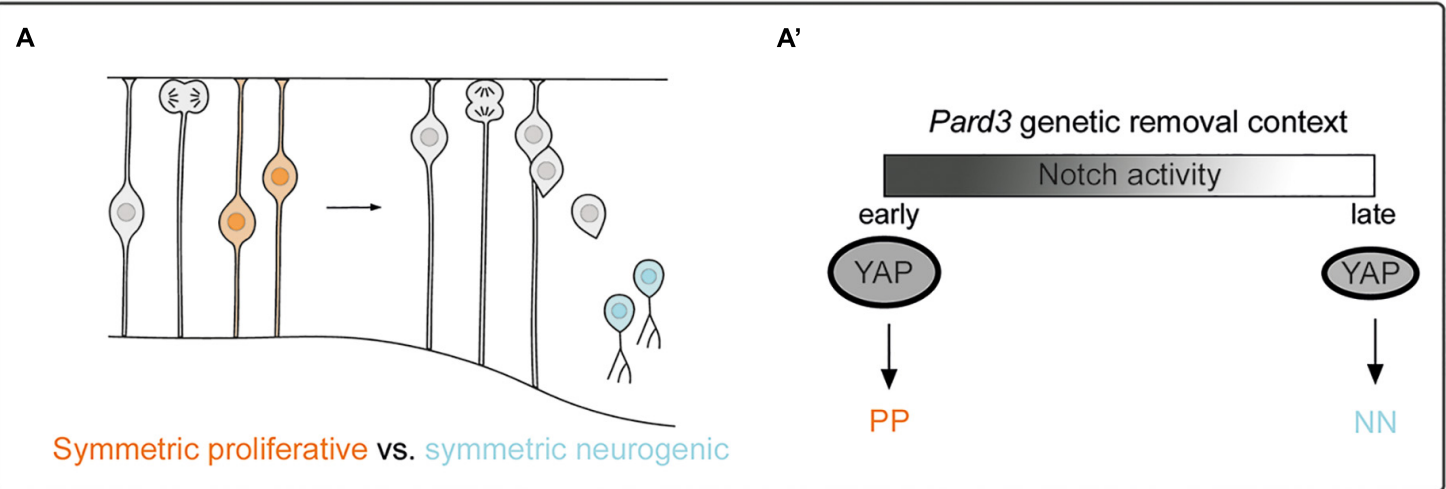

FIGURE 3 | Mechanosensing in the control of cell fate decisions: Notch pathway being upstream of YAP/TAZ. (A) Schematic representation of a mouse embryonic cortex. Progenitor cells from a symmetric proliferative division are depicted in orange and two neurons deriving from a symmetric neurogenic division are depicted in blue. (A') Scheme of cell division modes in the Pard3 genetic deletion context. At the early neurogenic phase, Notch activity increases YAP expression and promotes symmetric proliferative divisions (orange). At late neurogenic phase, the decrease of Notch activity results in lower YAP expression and the promotion of symmetric neurogenic divisions (blue) (Liu et al., 2018).

in muscle progenitors decrease upon muscle immobilization (Esteves de Lima et al., 2016). Overall, YAP-TEAD drives Jag2 expression in muscle fibers upon muscle contraction, as a result, Jag2 activates Notch in neighboring cells, maintaining the muscle progenitor cell pool in a non-cell-autonomous manner (Figures 2A,A').

The YAP/TAZ-TEAD and Notch pathways do not always have synergic functions. In the epidermis, basal progenitors specify from the basement membrane to the tissue surface. Notch signaling participates in the cell decision between basal progenitor and the epidermal fate. The NICD-RBPJ complex drives the expression of epidermal differentiation genes (Blanpain et al., 2006). Low cell density or high ECM rigidity trigger YAP/TAZ-TEAD activation in basal progenitors leading to progenitor maintenance through the inhibition of Notch signaling, as shown both in vitro and in vivo (Totaro et al., 2017). This process is cell-cell contact independent. In basal progenitors, the YAP/TAZ-TEAD complex activates the transcription of Dll1 and Dll3; thereafter, cis interactions of Dll1 and Dll3 with Notch receptors can block Notch activation, thus, preventing epidermal differentiation. Altogether, YAP/TAZTEAD controls epidermal fate decisions by inhibiting Notch signaling downstream of mechanical signals in a cell-autonomous manner (Figures 2B, B').

\section{Notch Pathway Being Upstream of YAP/TAZ}

Notch can be upstream of YAP/TAZ during embryonic brain development. Asymmetric divisions play a role in the balance between cell proliferation and differentiation. Radial glial progenitors (RGPs) divide asymmetrically to give rise to a neuron and another RGP. The polarity gene Pard 3 is highly expressed in the apical cell surface and regulates asymmetric divisions in RGPs in the mammalian cortex (Costa et al., 2008). Pard3 removal by genetic depletion in mice leads to temporally distinct changes in RGP mitotic behavior: at the early neurogenic phase, it results in increased YAP expression and promotes symmetric proliferative divisions, while at late neurogenic phase, it results in decreased YAP expression and promotes RGP symmetric differentiation divisions. Notch expression decreases during cortical development, coinciding with the RGPs behavioral switch. Accordingly, Notch promotes high YAP levels in the nucleus upon Pard3 removal (Liu et al., 2018). This activation could be through the binding of the NICD-RBPJ complex to the YAP promoter, as described in neural stem cells (Li et al., 2012). Thus, the interplay of Pard3 with Notch and YAP/TAZ could explain the potential role that mechanical signals play in this process. Altogether, the Notch pathway upstream of YAP/TAZ controls the division cell mode and, therefore, cell fate in the developing cortex (Figures $3 \mathbf{A}, \mathbf{A}^{\prime}$ ).

\section{THE LINK BETWEEN MORPHOGENETIC CHANGES AND CELL FATE}

Mechanical forces can control cell fate decisions. Seminal studies have widely demonstrated how mechanical signals influence the lineage commitment of multipotent stem cells (Sordella et al., 2003; McBeath et al., 2004; Hong et al., 2005; Engler et al., 2006; Kilian et al., 2010; Dupont et al., 2011; Tang et al., 2013). However, an important question that remains is how the morphogenetic tissue changes are intertwined with cell fate decisions during embryonic development. For this, several challenges need to be addressed, such as understanding the modulation of forces in embryos in vivo and how they result in distinct cell fates upon morphogenesis. Thus, the advancement 
in new techniques to study and manipulate mechanical forces in complex 3D structures in vivo will be crucial to elucidate how tissue morphogenesis and cell fate decisions are coupled. In the meantime, the best approach is to combine in vitro approaches, which allow mechanical forces to be precisely manipulated, with in vivo studies, which provide the whole tissue context. In this way, we can gain a better understanding of the interactions between the different cell types and their environment as well as of the mechanisms operating downstream of mechanical signals.

Interplay between Notch and YAP/TAZ can mediate the role of mechanical forces in binary cell fate decisions (see section "Mechanosensing in the Control of Cell Fate Decisions"), and it plays an important role in different pathologies, adult homeostasis, and regeneration (Totaro et al., 2018a). However, the role of TAZ has not been assessed in many developmental contexts, and in most of the cases the main functions have been associated to YAP. YAP and TAZ can act both redundantly, but also in a specific manner (Morin-Kensicki et al., 2006; Hossain et al., 2007; Makita et al., 2008; Reginensi et al., 2013; Talwar et al., 2021), depending on the biological process. An open question is whether YAP and TAZ act together in systems where the robustness needs to be maintained, or whether they have specific attributed roles. Along this line, future studies are needed as well to uncover whether TAZ can also form transcriptional complexes with NICD-RBPJ or HES1, or whether this is a specific YAP property. Remarkably, the interplay between Notch and YAP/TAZ results in cooperation in most developmental scenarios. This cooperation arises as a relevant mechanism to explain the missing link between mechanical cues and cell fate decisions in developing tissues.

Cell specification and proliferation are intertwined processes. YAP/TAZ are regulators of progenitor cell proliferation downstream of mechanical signals (Hansen et al., 2015), while Notch is known as the main regulator of binary cell fate decisions (Artavanis-Tsakonas et al., 1999). How do both pathways coordinate cell proliferation and specification during morphogenesis? Is the interplay between YAP/TAZ and Notch a common mechanism of most developing tissues? There are several speculative scenarios. Notch could operate first to establish a given cell fate. Then, this fate could be maintained by YAP/TAZ and the cell population would expand. On the other hand, mechanical signals could trigger YAP/TAZ activity to promote the maintenance and proliferation of the given cell population, until Notch activates the transition of cells toward specification and differentiation. In this case, YAP/TAZ may either activate or inhibit Notch signaling to start this

\section{REFERENCES}

Aragona, M., Panciera, T., Manfrin, A., Giulitti, S., Michielin, F., Elvassore, N., et al. (2013). A mechanical checkpoint controls multicellular growth through YAP/TAZ regulation by actin-processing factors. Cell 154, 1047-1059. doi: 10. 1016/j.cell.2013.07.042

Artavanis-Tsakonas, S., Rand, M. D., and Lake, R. J. (1999). Notch signaling: cell fate control and signal integration in development. Science 284, 770-776. doi: 10.1126/science.284.5415. 770 transition. In both scenarios, Notch and YAP/TAZ can cooperate to either repress or drive a given cell fate. However, Notch and YAP/TAZ can control the fate and proliferation of the same cell population by different and parallel mechanisms. This could explain how YAP/TAZ can control cell fate independently of Notch signaling and how Notch can act as a mechanosensor independently of YAP/TAZ. Therefore, the cooperative role of Notch and YAP/TAZ downstream of mechanical signals could shed light into the coordination between cell specification and proliferation. Moreover, the role of other players in the interplay between Notch and YAP/TAZ illustrates another layer of complexity in their regulation and highlights their crucial role in the integration of extrinsic and intrinsic inputs. Altogether, Notch and YAP/TAZ interplay allows a better understanding of the pleiotropic effects of both pathways during development. Thus, Notch and YAP/TAZ interplay could be seen as a core mechanism linking mechanical cues and binary cell fate decisions. Nevertheless, their independent functions and the interplay with other signaling pathways points to a model with higher complexity. Further studies need to be conducted to uncover the regulation and roles of Notch and YAP/TAZ during vertebrate development.

\section{AUTHOR CONTRIBUTIONS}

CE-P and CP contributed to the concept, design, and writing of the review. Both authors contributed to the article and approved the submitted version.

\section{FUNDING}

This work was funded by the Agencia Española de Investigación AEI-PGC2018-095663-B-I00 and RED2018-102553-T grants (MICIU-FEDER) to CP. DCEXS-UPF is a Unidad de Excelencia María de Maeztu funded by the AEI (CEX2018-000792-M). CE-P is a recipient of a predoctoral FPU fellowship from the Spanish Ministry of Universities (FPU17/06034). CP is a recipient of ICREA Academia award (Generalitat de Catalunya).

\section{ACKNOWLEDGMENTS}

The authors would like to thank the members of the lab for critical discussions and insight. et al. (2009). The notch ligands Dll4 and Jagged1 have opposing effects on angiogenesis. Cell 137, 1124-1135. doi: 10.1016/j.cell.2009.03.025

Benham-Pyle, B. W., Pruitt, B. L., and Nelson, W. J. (2015). Cell adhesion. Mechanical strain induces E-cadherin-dependent Yap1 and $\beta$-catenin activation to drive cell cycle entry. Science 348, 1024-1027. doi: 10.1126/science.aaa4 559

Bessho, Y., Hirata, H., Masamizu, Y., and Kageyama, R. (2003). Periodic repression by the bHLH factor Hes7 is an essential mechanism for the somite segmentation clock. Genes Dev. 17, 1451-1456. doi: 10.1101/gad.1092303 
Beyer, T. A., Weiss, A., Khomchuk, Y., Huang, K., Ogunjimi, A. A., Varelas, X., et al. (2013). Switch enhancers interpret TGF- $\beta$ and Hippo signaling to control cell fate in human embryonic stem cells. Cell Rep. 5, 1611-1624. doi: 10.1016/j. celrep.2013.11.021

Blanpain, C., Lowry, W. E., Pasolli, H. A., and Fuchs, E. (2006). Canonical notch signaling functions as a commitment switch in the epidermal lineage. Genes Dev. 20, 3022-3035. doi: 10.1101/gad.1477606

Bray, S. J. (2016). Notch signaling in context. Nat. Rev. Mol. Cell Biol. 17, 722-735. doi: $10.1038 /$ nrm.2016.94

Camargo, F. D., Gokhale, S., Johnnidis, J. B., Fu, D., Bell, G. W., Jaenisch, R., et al. (2007). YAP1 increases organ size and expands undifferentiated progenitor cells. Curr. Biol. 17, 2054-2060. doi: 10.1016/j.cub.2007.10.039

Cao, X., Pfaff, S. L., and Gage, F. H. (2008). YAP regulates neural progenitor cell number via the TEA domain transcription factor. Genes Dev. 22, 3320-3334. doi: 10.1101/gad.1726608

Caolo, V., Debant, M., Endesh, N., Futers, T. S., Lichtenstein, L., Bartoli, F., et al. (2020). Shear stress activates ADAM10 sheddase to regulate Notch1 via the Piezo1 force sensor in endothelial cells. eLife 9:e50684. doi: 10.7554/eLife.50684

Caolo, V., van den Akker, N. M., Verbruggen, S., Donners, M. M., Swennen, G., Schulten, H., et al. (2010). Feed-forward signaling by membrane-bound ligand receptor circuit: the case of NOTCH DELTA-like 4 ligand in endothelial cells. J. Biol. Chem. 285, 40681-40689. doi: 10.1074/jbc.M110.176065

Cebola, I., Rodríguez-Seguí, S. A., Cho, C. H.-H., Bessa, J., Rovira, M., Luengo, M., et al. (2015). TEAD and YAP regulate the enhancer network of human embryonic pancreatic progenitors. Nat. Cell Biol. 17, 615-626. doi: 10.1038/ ncb3160

Chang, L., Azzolin, L., Di Biagio, D., Zanconato, F., Battilana, G., Lucon Xiccato, R., et al. (2018). The SWI/SNF complex is a mechanoregulated inhibitor of YAP and TAZ. Nature 563, 265-269. doi: 10.1038/s41586-018-0658-1

Chowdhury, F., Li, I. T. S., Ngo, T. T. M., Leslie, B. J., Kim, B. C., Sokoloski, J. E., et al. (2016). Defining single molecular forces required for notch activation using nano yoyo. Nano Lett. 16, 3892-3897. doi: 10.1021/acs.nanolett.6b01 403

Cockburn, K., Biechele, S., Garner, J., and Rossant, J. (2013). The hippo pathway member Nf2 is required for inner cell mass specification. Curr. Biol. 23, 1195-1201. doi: 10.1016/j.cub.2013.05.044

Collinet, C., and Lecuit, T. (2021). Programmed and self-organized flow of information during morphogenesis. Nat. Rev. Mol. Cell Biol. 22, 245-265. doi: 10.1038/s41580-020-00318-6

Costa, M. R., Wen, G., Lepier, A., Schroeder, T., and Götz, M. (2008). Par-complex proteins promote proliferative progenitor divisions in the developing mouse cerebral cortex. Development 135, 11-22. doi: 10.1242/dev.009951

Cotton, J. L., Li, Q., Ma, L., Park, J.-S., Wang, J., Ou, J., et al. (2017). YAP/TAZ and hedgehog coordinate growth and patterning in gastrointestinal mesenchyme. Dev. Cell 43, 35-47. doi: 10.1016/j.devcel.2017.08.019

de Celis, J. F., and Bray, S. (1997). Feed-back mechanisms affecting Notch activation at the dorsoventral boundary in the Drosophila wing. Development 124, 3241-3251. doi: 10.1242/dev.124.17.3241

Dingare, C., Niedzwetzki, A., Klemmt, P. A., Godbersen, S., Fuentes, R., Mullins, M. C., et al. (2018). The Hippo pathway effector Taz is required for cell morphogenesis and fertilization in zebrafish. Development 145:dev167023. doi: $10.1242 /$ dev. 167023

Dong, J., Feldmann, G., Huang, J., Wu, S., Zhang, N., Comerford, S. A., et al. (2007). Elucidation of a universal size-control mechanism in Drosophila and mammals. Cell 130, 1120-1133. doi: 10.1016/j.cell.2007.07.019

Dupont, S., Morsut, L., Aragona, M., Enzo, E., Giulitti, S., Cordenonsi, M., et al. (2011). Role of YAP/TAZ in mechanotransduction. Nature 474, 179-183. doi: 10.1038/nature10137

Elosegui-Artola, A., Andreu, I., Beedle, A. E. M., Lezamiz, A., Uroz, M., Kosmalska, A. J., et al. (2017). Force triggers YAP nuclear entry by regulating transport across nuclear pores. Cell 171, 1397-1410.e14. doi: 10.1016/j.cell.2017.10.008

Elosegui-Artola, A., Oria, R., Chen, Y., Kosmalska, A., Pérez-González, C., Castro, N., et al. (2016). Mechanical regulation of a molecular clutch defines force transmission and transduction in response to matrix rigidity. Nat. Cell Biol. 18, 540-548. doi: 10.1038/ncb3336

Endo, K., Karim, M. R., Taniguchi, H., Krejci, A., Kinameri, E., Siebert, M., et al. (2011). Chromatin modification of Notch targets in olfactory receptor neuron diversification. Nat. Neurosci. 15, 224-233. doi: 10.1038/nn.2998
Engler, A. J., Sen, S., Sweeney, H. L., and Discher, D. E. (2006). Matrix elasticity directs stem cell lineage specification. Cell 126, 677-689. doi: 10.1016/j.cell. 2006.06.044

Esteves de Lima, J., Bonnin, M.-A., Birchmeier, C., and Duprez, D. (2016). Muscle contraction is required to maintain the pool of muscle progenitors via YAP and NOTCH during fetal myogenesis. eLife 5:e15593. doi: 10.7554/eLife.15593

Galli, G. G., Carrara, M., Yuan, W.-C., Valdes-Quezada, C., Gurung, B., PepeMooney, B., et al. (2015). YAP drives growth by controlling transcriptional pause release from dynamic enhancers. Mol. Cell 60, 328-337. doi: 10.1016/j. molcel.2015.09.001

Gazave, E., Lapébie, P., Richards, G. S., Brunet, F., Ereskovsky, A. V., Degnan, B. M., et al. (2009). Origin and evolution of the Notch signaling pathway: an overview from eukaryotic genomes. BMC Evol. Biol. 9:249. doi: 10.1186/1471-2148-9249

Gnedeva, K., Wang, X., McGovern, M. M., Barton, M., Tao, L., Trecek, T., et al. (2020). Organ of Corti size is governed by Yap/Tead-mediated progenitor selfrenewal. Proc. Natl. Acad. Sci. U.S.A. 117, 13552-13561. doi: 10.1073/pnas. 2000175117

Gordon, W. R., Zimmerman, B., He, L., Miles, L. J., Huang, J., Tiyanont, K., et al. (2015). Mechanical allostery: evidence for a force requirement in the proteolytic activation of Notch. Dev. Cell 33, 729-736. doi: 10.1016/j.devcel.2015.05.004

Han, D., Byun, S. H., Park, S., Kim, J., Kim, I., Ha, S., et al. (2015). YAP/TAZ enhance mammalian embryonic neural stem cell characteristics in a Teaddependent manner. Biochem. Biophys. Res. Commun. 458, 110-116. doi: 10. 1016/j.bbrc.2015.01.077

Hansen, C. G., Moroishi, T., and Guan, K.-L. (2015). YAP and TAZ: a nexus for Hippo signaling and beyond. Trends Cell Biol. 25, 499-513. doi: 10.1016/j.tcb. 2015.05.002

Hartman, B. H., Reh, T. A., and Bermingham-McDonogh, O. (2010). Notch signaling specifies prosensory domains via lateral induction in the developing mammalian inner ear. Proc. Natl. Acad. Sci. U.S.A. 107, 15792-15797. doi: $10.1073 /$ pnas. 1002827107

Heallen, T., Zhang, M., Wang, J., Bonilla-Claudio, M., Klysik, E., Johnson, R. L., et al. (2011). Hippo pathway inhibits Wnt signaling to restrain cardiomyocyte proliferation and heart size. Science 332, 458-461. doi: 10.1126/science.1199010

Heer, N. C., and Martin, A. C. (2017). Tension, contraction and tissue morphogenesis. Development 144, 4249-4260. doi: 10.1242/dev.151282

Heisenberg, C.-P., and Bellaïche, Y. (2013). Forces in tissue morphogenesis and patterning. Cell 153, 948-962. doi: 10.1016/j.cell.2013.05.008

Heng, B. C., Zhang, X., Aubel, D., Bai, Y., Li, X., Wei, Y., et al. (2021). An overview of signaling pathways regulating YAP/TAZ activity. Cell. Mol. Life Sci. 78, 497-512. doi: 10.1007/s00018-020-03579-8

Henrique, D., and Schweisguth, F. (2019). Mechanisms of Notch signaling: a simple logic deployed in time and space. Development 146:dev172148. doi: 10.1242/ dev. 172148

High, F. A., Zhang, M., Proweller, A., Tu, L., Parmacek, M. S., Pear, W. S., et al. (2007). An essential role for Notch in neural crest during cardiovascular development and smooth muscle differentiation. J. Clin. Invest. 117, 353-363. doi: 10.1172/JCI30070

Hilman, D., and Gat, U. (2011). The evolutionary history of YAP and the hippo/YAP pathway. Mol. Biol. Evol. 28, 2403-2417. doi: 10.1093/molbev/ msr065

Hirata, H., Yoshiura, S., Ohtsuka, T., Bessho, Y., Harada, T., Yoshikawa, K., et al. (2002). Oscillatory expression of the bHLH factor Hes1 regulated by a negative feedback loop. Science 298, 840-843. doi: 10.1126/science.1074560

Hirate, Y., Hirahara, S., Inoue, K., Suzuki, A., Alarcon, V. B., Akimoto, K., et al. (2013). Polarity-dependent distribution of angiomotin localizes Hippo signaling in preimplantation embryos. Curr. Biol. 8, 1181-1194. doi: 10.1016/j. cub.2013.05.014

Hong, J. H., Hwang, E. S., McManus, M. T., Amsterdam, A., Tian, Y., Kalmukova, R., et al. (2005). TAZ, a transcriptional modulator of mesenchymal stem cell differentiation. Science 309, 1074-1078. doi: 10.1126/science.1110955

Hossain, Z., Ali, S. M., Ko, H. L., Xu, J., Ng, C. P., Guo, K., et al. (2007). Glomerulocystic kidney disease in mice with a targeted inactivation of Wwtr1. Proc. Natl. Acad. Sci. U.S.A. 104, 1631-1636. doi: 10.1073/pnas.0605266104

Huang, Z., Hu, J., Pan, J., Wang, Y., Hu, G., Zhou, J., et al. (2016). YAP stabilizes SMAD1 and promotes BMP2-induced neocortical astrocytic differentiation. Development 143, 2398-2409. doi: 10.1242/dev.130658 
Hubaud, A., Regev, I., Mahadevan, L., and Pourquié, O. (2017). Excitable dynamics and Yap-dependent mechanical cues drive the segmentation clock. Cell 171, 668-682.e11. doi: 10.1016/j.cell.2017.08.043

Jahnsen, E. D., Trindade, A., Zaun, H. C., Lehoux, S., Duarte, A., and Jones, E. A. (2015). Notch1 is pan-endothelial at the onset of flow and regulated by flow. PLoS One 10:e0122622. doi: 10.1371/journal.pone.0122622

Kageyama, R., Ohtsuka, T., and Kobayashi, T. (2007). The Hes gene family: repressors and oscillators that orchestrate embryogenesis. Development 134, 1243-1251. doi: 10.1242/dev.000786

Kilian, K. A., Bugarija, B., Lahn, B. T., and Mrksich, M. (2010). Geometric cues for directing the differentiation of mesenchymal stem cells. Proc. Natl. Acad. Sci. U.S.A. 107, 4872-4877. doi: 10.1073/pnas. 0903269107

Kim, J. Y., Park, R., Lee, J. H., Shin, J., Nickas, J., Kim, S., et al. (2016). Yap is essential for retinal progenitor cell cycle progression and RPE cell fate acquisition in the developing mouse eye. Dev. Biol. 419, 336-347. doi: 10.1016/ j.ydbio.2016.09.001

Kim, M., Kim, T., Johnson, R. L., and Lim, D. S. (2015). Transcriptional corepressor function of the Hippo pathway transducers YAP and TAZ. Cell Rep. 11, 270-282. doi: 10.1016/j.celrep.2015.03.015

Kim, N. G. and Gumbiner, B. M. (2015). Adhesion to fibronectin regulates Hippo signaling via the FAK-Src-PI3K pathway. J. Cell. Biol. 210, 503-515. doi: 10. 1083/jcb.201501025

Kodama, Y., Hijikata, M., Kageyama, R., Shimotohno, K., and Chiba, T. (2004). The role of notch signaling in the development of intrahepatic bile ducts. Gastroenterology 127, 1775-1786. doi: 10.1053/j.gastro.2004.09.004

Kostic, M., Paridaen, J. T. M. L., Long, K. R., Kalebic, N., Langen, B., Grübling, N., et al. (2019). YAP activity is necessary and sufficient for basal progenitor abundance and proliferation in the developing neocortex. Cell Rep. 27, 11031118. doi: 10.1016/j.celrep.2019.03.091

Kumar, A., Placone, J. K., and Engler, A. J. (2017). Understanding the extracellular forces that determine cell fate and maintenance. Development 144, 4261-4270. doi: $10.1242 /$ dev.158469

Labernadie, A., and Trepat, X. (2018). Sticking, steering, squeezing and shearing: cell movements driven by heterotypic mechanical forces. Curr. Opin. Cell Biol. 54, 57-65. doi: 10.1016/j.ceb.2018.04.008

Lahmann, I., Bröhl, D., Zyrianova, T., Isomura, A., Czajkowski, M. T., Kapoor, V., et al. (2019). Oscillations of $\mathrm{MyoD}$ and Hesl proteins regulate the maintenance of activated muscle stem cells. Genes Dev. 33, 524-535. doi: 10.1101/gad.322818. 118

Lavado, A., He, Y., Paré, J., Neale, G., Olson, E. N., Giovannini, M., et al. (2013). Tumor suppressor Nf2 limits expansion of the neural progenitor pool by inhibiting Yap/Taz transcriptional coactivators. Development 140, 3323-3334. doi: $10.1242 /$ dev.096537

Lavado, A., Park, J. Y., Paré, J., Finkelstein, D., Pan, H., Xu, B., et al. (2018). The Hippo pathway prevents YAP/TAZ-driven hypertranscription and controls neural progenitor number. Dev. Cell 47, 576-591.e8. doi: 10.1016/j.devcel.2018. 09.021

Lee, D. H., Park, J. O., Kim, T. S., Kim, S. K., Kim, T. H., Kim, M. C., et al. (2016). LATS-YAP/TAZ controls lineage specification by regulating TGF $\beta$ signaling and $\mathrm{Hnf} 4 \alpha$ expression during liver development. Nat. Commun. 7:11961.

Lee, K. K., and Yonehara, S. (2012). Identification of mechanism that couples multisite phosphorylation of Yes-associated protein (YAP) with transcriptional coactivation and regulation of apoptosis. J. Biol. Chem. 287, 9568-9578. doi: 10.1074/jbc.M111.296954

Lee, K. P., Lee, J. H., Kim, T. S., Kim, T. H., Park, H. D., Byun, J. S., et al. (2010). The Hippo-Salvador pathway restrains hepatic oval cell proliferation, liver size, and liver tumorigenesis. Proc. Natl. Acad. Sci. U.S.A. 107, 8248-8253. doi: 10.1073/pnas.0912203107

Lei, Q.-Y., Zhang, H., Zhao, B., Zha, Z.-Y., Bai, F., Pei, X.-H., et al. (2008). TAZ promotes cell proliferation and epithelial-mesenchymal transition and is inhibited by the hippo pathway. Mol. Cell. Biol. 28, 2426-2436. doi: 10.1128/ MCB.01874-07

Leung, C. Y., and Zernicka-Goetz, M. (2013). Angiomotin prevents pluripotent lineage differentiation in mouse embryos via hippo pathway-dependent and -independent mechanisms. Nat. Commun. 4:2251. doi: 10.1038/ncomms3 251
Li, C. Y., Hu, J., Lu, H., Lan, J., Du, W., Galicia, N., et al. (2016). $\alpha$ E-catenin inhibits YAP/TAZ activity to regulate signalling centre formation during tooth development. Nat. Commun. 13:12133. doi: 10.1038/ncomms12133

Li, Y., Hibbs, M. A., Gard, A. L., Shylo, N. A., and Yun, K. (2012). Genome-wide analysis of N1ICD/RBPJ targets in vivo reveals direct transcriptional regulation of Wnt, SHH, and Hippo pathway effectors by Notch1. Stem Cells 30, 741-752. doi: $10.1002 /$ stem. 1030

Lian, I., Kim, J., Okazawa, H., Zhao, J., Zhao, B., Yu, J., et al. (2010). The role of YAP transcription coactivator in regulating stem cell self-renewal and differentiation. Genes Dev. 24, 1106-1118. doi: 10.1101/gad.1903310

Lin, C., Yao, E., Zhang, K., Jiang, X., Croll, S., Thompson-Peer, K., et al. (2017). YAP is essential for mechanical force production and epithelial cell proliferation during lung branching morphogenesis. eLife 6:14665. doi: 10.7554/eLife.21130

Liu, W. A., Chen, S., Li, Z., Lee, C. H., Mirzaa, G., Dobyns, W. B., et al. (2018). PARD3 dysfunction in conjunction with dynamic HIPPO signaling drives cortical enlargement with massive heterotopia. Genes Dev. 32, 763-780. doi: $10.1101 /$ gad. 313171.118

Lloyd-Lewis, B., Mourikis, P., and Fre, S. (2019). Notch signalling: sensor and instructor of the microenvironment to coordinate cell fate and organ morphogenesis. Curr. Opin. Cell Biol. 61, 16-23. doi: 10.1016/j.ceb.2019.06.003

Loerakker, S., Stassen, O. M. J. A., Ter Huurne, F. M., Boareto, M., Bouten, C. V. C., and Sahlgren, C. M. (2018). Mechanosensitivity of Jagged-Notch signaling can induce a switch-type behavior in vascular homeostasis. Proc. Natl. Acad. Sci. U.S.A. 115, E3682-E3691. doi: 10.1073/pnas.1715277115

Lorthongpanich, C., Messerschmidt, D. M., Chan, S. W., Hong, W., Knowles, B. B., and Solter, D. (2013). Temporal reduction of LATS kinases in the early preimplantation embryo prevents ICM lineage differentiation. Genes Dev. 27, 1441-1446. doi: 10.1101/gad.219618.113

Lu, L., Li, Y., Kim, S. M., Bossuyt, W., Liu, P., Qiu, Q., et al. (2010). Hippo signaling is a potent in vivo growth and tumor suppressor pathway in the mammalian liver. Proc. Natl. Acad. Sci. U.S.A. 107, 1437-1442. doi: 10.1073/ pnas. 0911427107

Lundin, V., Sugden, W. W., Theodore, L. N., Sousa, P. M., Han, A., Chou, S., et al. (2020). YAP regulates hematopoietic stem cell formation in response to the biomechanical forces of blood flow. Dev. Cell 52, 446-460.e5. doi: 10.1016/ j.devcel.2020.01.006

Mack, J. J., Mosqueiro, T. S., Archer, B. J., Jones, W. M., Sunshine, H., Faas, G. C., et al. (2017). NOTCH1 is a mechanosensor in adult arteries. Nat. Commun. 8:1620. doi: 10.1038/s41467-017-01741-8

Mahoney, J. E., Mori, M., Szymaniak, A. D., Varelas, X., and Cardoso, W. V. (2014). The Hippo pathway effector Yap controls patterning and differentiation of airway epithelial progenitors. Dev. Cell 30, 137-150. doi: 10.1016/j.devcel. 2014.06.003

Makita, R., Uchijima, Y., Nishiyama, K., Amano, T., Chen, Q., Takeuchi, T., et al. (2008). Multiple renal cysts, urinary concentration defects, and pulmonary emphysematous changes in mice lacking TAZ. Am. J. Physiol. Renal Physiol. 294, F542-F553. doi: 10.1152/ajprenal.00201.2007

Mamidi, A., Prawiro, C., Seymour, P. A., de Lichtenberg, K. H., Jackson, A., Serup, P., et al. (2018). Mechanosignalling via integrins directs fate decisions of pancreatic progenitors. Nature 564, 114-118. doi: 10.1038/s41586-018-0762-2

Manderfield, L. J., Aghajanian, H., Engleka, K. A., Lim, L. Y., Liu, F., Jain, R., et al. (2015). Hippo signaling is required for Notch-dependent smooth muscle differentiation of neural crest. Development 142, 2962-2971. doi: 10.1242/dev. 125807

Manderfield, L. J., High, F. A., Engleka, K. A., Liu, F., Li, L., Rentschler, S., et al. (2012). Notch activation of Jagged 1 contributes to the assembly of the arterial wall. Circulation 125, 314-323. doi: 10.1161/CIRCULATIONAHA.111.047159

Masamizu, Y., Ohtsuka, T., Takashima, Y., Nagahara, H., Takenaka, Y., Yoshikawa, K., et al. (2006). Real-time imaging of the somite segmentation clock: revelation of unstable oscillators in the individual presomitic mesoderm cells. Proc. Natl. Acad. Sci. U.S.A. 103, 1313-1318. doi: 10.1073/pnas.0508658103

McBeath, R., Pirone, D. M., Nelson, C. M., Bhadriraju, K., and Chen, C. S. (2004). Cell shape, cytoskeletal tension, and RhoA regulate stem cell lineage commitment. Dev. Cell 6, 483-495. doi: 10.1016/s1534-5807(04)00075-9

Menchero, S., Rollan, I., Lopez-Izquierdo, A., Andreu, M. J., Sainz de Aja, J., Kang, M., et al. (2019). Transitions in cell potency during early mouse development are driven by Notch. eLife 8:2813. doi: 10.7554/eLife.42930 
Meng, Z., Qiu, Y., Lin, K. C., Kumar, A., Placone, J. K., Fang, C., et al. (2018). RAP2 mediates mechanoresponses of the Hippo pathway. Nature 15:802. doi: 10.1038/s41586-018-0444-0

Micchelli, C. A., Rulifson, E. J., and Blair, S. S. (1997). The function and regulation of cut expression on the wing margin of Drosophila: Notch, wingless and a dominant negative role for Delta and Serrate. Development 124, 1485-1495. doi: 10.1242/dev.124.8.1485

Miesfeld, J. B., Gestri, G., Clark, B. S., Flinn, M. A., Poole, R. J., Bader, J. R., et al. (2015). Yap and Taz regulate retinal pigment epithelial cell fate. Development 142, 3021-3032. doi: 10.1242/dev.119008

Morin-Kensicki, E. M., Boone, B. N., Howell, M., Stonebraker, J. R., Teed, J., Alb, J. G., et al. (2006). Defects in yolk sac vasculogenesis, chorioallantoic fusion, and embryonic axis elongation in mice with targeted disruption of Yap65. Mol. Cell. Biol. 26, 77-87. doi: 10.1128/mcb.26.1.77-87.2006

Nakajima, H., Yamamoto, K., Agarwala, S., Terai, K., Fukui, H., Fukuhara, S., et al. (2017). Flow-dependent endothelial YAP regulation contributes to vessel maintenance. Dev. Cell 40, 523-536.e6. doi: 10.1016/j.devcel.2017.02.019

Nandagopal, N., Santat, L. A., LeBon, L., Sprinzak, D., Bronner, M. E., and Elowitz, M. B. (2018). Dynamic ligand discrimination in the Notch signaling pathway. Cell 172, 869-880.e19. doi: 10.1016/j.cell.2018.01.002

Nandagopal, N., Santat, L. A., and Elowitz, M. B.(2019). Cis-activation in the Notch signaling pathway. Elife. 8:e37880. doi: 10.7554/eLife.37880

Nardone, G., Oliver-De La Cruz, J., Vrbsky, J., Martini, C., Pribyl, J., Skládal, P., et al. (2017). YAP regulates cell mechanics by controlling focal adhesion assembly. Nat. Commun. 8:15321. doi: 10.1038/ncomms15321

Nishioka, N., Inoue, K.-I., Adachi, K., Kiyonari, H., Ota, M., Ralston, A., et al. (2009). The Hippo signaling pathway components Lats and Yap pattern Tead4 activity to distinguish mouse trophectoderm from inner cell mass. Dev. Cell 16, 398-410. doi: 10.1016/j.devcel.2009.02.003

Okigawa, S., Mizoguchi, T., Okano, M., Tanaka, H., Isoda, M., Jiang, Y.-J., et al. (2014). Different combinations of Notch ligands and receptors regulate V2 interneuron progenitor proliferation and V2a/V2b cell fate determination. Dev. Biol. 391, 196-206. doi: 10.1016/j.ydbio.2014.04.011

Ota, M., and Sasaki, H. (2008). Mammalian Tead proteins regulate cell proliferation and contact inhibition as transcriptional mediators of Hippo signaling. Development 135, 4059-4069. doi: 10.1242/dev.027151

Panciera, T., Azzolin, L., Cordenonsi, M., and Piccolo, S. (2017). Mechanobiology of YAP and TAZ in physiology and disease. Nat. Rev. Mol. Cell Biol. 18, 758-770. doi: 10.1038/nrm.2017.87

Panin, V. M., Papayannopoulos, V., Wilson, R., and Irvine, K. D. (1997). Fringe modulates Notch-ligand interactions. Nature 387, 908-912. doi: 10.1038/43191

Pathak, M. M., Nourse, J. L., Tran, T., Hwe, J., Arulmoli, J., Le, D. T. T., et al. (2014). Stretch-activated ion channel Piezol directs lineage choice in human neural stem cells. Proc. Natl. Acad. Sci. U.S.A. 111, 16148-16153. doi: 10.1073/ pnas. 1409802111

Petrovic, J., Formosa-Jordan, P., Luna-Escalante, J. C., Abelló, G., Ibañes, M., Neves, J., et al. (2014). Ligand-dependent Notch signaling strength orchestrates lateral induction and lateral inhibition in the developing inner ear. Development 141, 2313-2324. doi: 10.1242/dev.108100

Plouffe, S. W., Hong, A. W., and Guan, K.-L. (2015). Disease implications of the Hippo/YAP pathway. Trends Mol. Med. 21, 212-222. doi: 10.1016/j.molmed. 2015.01.003

Pocaterra, A., Romani, P., and Dupont, S. (2020). YAP/TAZ functions and their regulation at a glance. J. Cell Sci. 133:jcs230425.

Pocaterra, A., Santinon, G., Romani, P., Brian, I., Dimitracopoulos, A., Ghisleni, A., et al. (2019). F-actin dynamics regulates mammalian organ growth and cell fate maintenance. J. Hepatol. 71, 130-142. doi: 10.1016/j.jhep.2019.02.022

Pocaterra, A., Scattolin, G., Romani, P., Ament, C., Ribback, S., Chen, X., et al. (2021). Fascin1 empowers YAP mechanotransduction and promotes cholangiocarcinoma development. Commun. Biol. 4:763.

Porazinski, S., Wang, H., Asaoka, Y., Behrndt, M., Miyamoto, T., Morita, H., et al. (2015). YAP is essential for tissue tension to ensure vertebrate 3D body shape. Nature 521, 217-221. doi: 10.1038/nature14215

Rayon, T., Menchero, S., Nieto, A., Xenopoulos, P., Crespo, M., Cockburn, K., et al. (2014). Notch and Hippo converge on Cdx2 to specify the trophectoderm lineage in the mouse blastocyst. Dev. Cell 30, 410-422. doi: 10.1016/j.devcel. 2014.06.019

Reginensi, A., Scott, R. P., Gregorieff, A., Bagherie-Lachidan, M., Chung, C., Lim, D.-S., et al. (2013). Yap- and Cdc42-dependent nephrogenesis and morphogenesis during mouse kidney development. PLoS Genet. 9:e1003380. doi: 10.1371/journal.pgen.1003380

Sebé-Pedrós, A., Zheng, Y., Ruiz-Trillo, I., and Pan, D. (2012). Premetazoan origin of the Hippo signaling pathway. Cell Rep. 1, 13-20. doi: 10.1016/j.celrep.2011. 11.004

Seymour, P. A., Collin, C. A., Egeskov-Madsen, A. L. R., Jørgensen, M. C., Shimojo, H., Imayoshi, I., et al. (2020). Jag1 modulates an oscillatory Dll1-Notch-Hes1 signaling module to coordinate growth and fate of pancreatic progenitors. Dev. Cell 52, 731-747.e8. doi: 10.1016/j.devcel.2020.01.015

Shaya, O., Binshtok, U., Hersch, M., Rivkin, D., Weinreb, S., Amir-Zilberstein, L., et al. (2017). Cell-cell contact area affects Notch signaling and Notchdependent patterning. Dev. Cell 40, 505-511.e6. doi: 10.1016/j.devcel.2017.02. 009

Shimojo, H., Ohtsuka, T., and Kageyama, R. (2008). Oscillations in Notch signaling regulate maintenance of neural progenitors. Neuron 58, 52-64. doi: 10.1016/j. neuron.2008.02.014

Sordella, R., Jiang, W., Chen, G. C., Curto, M., and Settleman, J. (2003). Modulation of Rho GTPase signaling regulates a switch between adipogenesis and myogenesis. Cell 113, 147-158. doi: 10.1016/s0092-8674(03)002 71-x

Stassen, O. M. J. A., Ristori, T., and Sahlgren, C. M. (2020). Notch in mechanotransduction - from molecular mechanosensitivity to tissue mechanostasis. J. Cell Sci. 133:jcs250738. doi: 10.1242/jcs.250738

Talwar, S., Kant, A., Xu, T., Shenoy, V. B., and Assoian, R. K. (2021). Mechanosensitive smooth muscle cell phenotypic plasticity emerging from a null state and the balance between Rac and Rho. Cell Rep. 35:109019. doi: 10.1016/j.celrep.2021.109019

Tang, Y., Rowe, R. G., Botvinick, E. L., Kurup, A., Putnam, A. J., Seiki, M., et al. (2013). MT1-MMP-dependent control of skeletal stem cell commitment via a $\beta 1$-integrin/YAP/TAZ signaling axis. Dev. Cell 25, 402-416. doi: 10.1016/j. devcel.2013.04.011

Thompson, D. W. (1917). On Growth and Form. Cambridge: Cambridge University Press.

Tiberi, L., van den Ameele, J., Dimidschstein, J., Piccirilli, J., Gall, D., Herpoel, A., et al. (2012). BCL6 controls neurogenesis through Sirt1-dependent epigenetic repression of selective Notch targets. Nat. Neurosci. 15, 1627-1635. doi: 10.1038/ nn. 3264

Totaro, A., Castellan, M., Battilana, G., Zanconato, F., Azzolin, L., Giulitti, S., et al. (2017). YAP/TAZ link cell mechanics to Notch signaling to control epidermal stem cell fate. Nat. Commun. 8:15206. doi: 10.1038/ncomms15206

Totaro, A., Castellan, M., Di Biagio, D., and Piccolo, S. (2018a). Crosstalk between YAP/TAZ and Notch signaling. Trends Cell Biol. 28, 560-573. doi: 10.1016/j.tcb. 2018.03 .001

Totaro, A., Panciera,T., and Piccolo, S. (2018b). YAP/TAZ upstream signals and downstream responses. Nat. Cell. Biol. 20, 888-899. doi: 10.1038/s41556-0180142-z

Tschaharganeh, D. F., Chen, X., Latzko, P., Malz, M., Gaida, M. M., Felix, K., et al. (2013). Yes-associated protein up-regulates Jagged-1 and activates the Notch pathway in human hepatocellular carcinoma. Gastroenterology 144, 1530-1542. doi: 10.1053/j.gastro.2013.02.009

Udan, R. S., Kango-Singh, M., Nolo, R., Tao, C., and Halder, G. (2003). Hippo promotes proliferation arrest and apoptosis in the Salvador/Warts pathway. Nat. Cell Biol. 5, 914-920. doi: 10.1038/ncb1050

Vasyutina, E., Lenhard, D. C., Wende, H., Erdmann, B., Epstein, J. A., and Birchmeier, C. (2007). RBP-J (Rbpsuh) is essential to maintain muscle progenitor cells and to generate satellite cells. Proc. Natl. Acad. Sci. U.S.A. 104, 4443-4448. doi: 10.1073/pnas.0610647104

Voltes, A., Hevia, C. F., Engel-Pizcueta, C., Dingare, C., Calzolari, S., Terriente, J., et al. (2019). YAP/TAZ-TEAD activity links mechanical cues to progenitor cell behavior during zebrafish hindbrain segmentation. Development 146:dev176735. doi: 10.1242/dev.176735

Wang, J., Xiao, Y., Hsu, C. W., Martinez-Traverso, I. M., Zhang, M., Bai, Y., et al. (2016). Yap and Taz play a crucial role in neural crest-derived craniofacial development. Development 143, 504-515. doi: 10.1242/dev.126 920

Watanabe, Y., Miyasaka, K. Y., Kubo, A., Kida, Y. S., Nakagawa, O., Hirate, Y., et al. (2017). Notch and Hippo signaling converge on Strawberry Notch 1 (Sbno1) to synergistically activate Cdx2 during specification of the trophectoderm. Sci. Rep. 7:46135. doi: 10.1038/srep46135 
Wu, N., Nguyen, Q., Wan, Y., Zhou, T., Venter, J., Frampton, G. A., et al. (2017). The Hippo signaling functions through the Notch signaling to regulate intrahepatic bile duct development in mammals. Lab. Invest. 97, 843-853. doi: 10.1038/labinvest.2017.29

Xia, P., Gütl, D., Zheden, V., and Heisenberg, C.-P. (2019). Lateral inhibition in cell specification mediated by mechanical signals modulating TAZ activity. Cell 176, 1379-1392.e14. doi: 10.1016/j.cell.2019.01.019

Yasuda, D., Kobayashi, D., Akahoshi, N., Ohto-Nakanishi, T., Yoshioka, K., Takuwa, Y., et al. (2019). Lysophosphatidic acid-induced YAP/TAZ activation promotes developmental angiogenesis by repressing Notch ligand Dll4. J. Clin. Invest. 129, 4332-4349. doi: 10.1172/JCI121955

Yimlamai, D., Christodoulou, C., Galli, G. G., Yanger, K., Pepe-Mooney, B., Gurung, B., et al. (2014). Hippo pathway activity influences liver cell fate. Cell 157, 1324-1338. doi: 10.1016/j.cell.2014.03.060

Yin, F., Yu, J., Zheng, Y., Chen, Q., Zhang, N., and Pan, D. (2013). Spatial organization of Hippo signaling at the plasma membrane mediated by the tumor suppressor Merlin/NF2. Cell 154, 1342-1355. doi: 10.1016/j.cell.2013.08. 025

Yu, F. X., Zhao, B., Panupinthu, N., Jewell, J. L., Lian, I., Wang, L. H., et al. (2012). Regulation of the Hippo-YAP pathway by G-protein-coupled receptor signaling. Cell 150, 780-791. doi: 10.1016/j.cell.2012.06.037

Zhang, N., Bai, H., David, K. K., Dong, J., Zheng, Y., Cai, J., et al. (2010). The Merlin/NF2 tumor suppressor functions through the YAP oncoprotein to regulate tissue homeostasis in mammals. Dev. Cell 19, 27-38. doi: 10.1016/j. devcel.2010.06.015

Zhao, B., Ye, X., Yu, J., Li, L., Li, W., Li, S., et al. (2008). TEAD mediates YAPdependent gene induction and growth control. Genes Dev. 22, 1962-1971. doi: $10.1101 /$ gad.1664408
Zheng, Y., and Pan, D. (2019). The Hippo signaling pathway in development and disease. Dev. Cell 50, 264-282. doi: 10.1016/j.devcel.2019.06.003

Zhou, D., Conrad, C., Xia, F., Park, J. S., Payer, B., Yin, Y., et al. (2009). Mst1 and Mst2 maintain hepatocyte quiescence and suppress hepatocellular carcinoma development through inactivation of the Yap1 oncogene. Cancer Cell 16, 425-438. doi: 10.1016/j.ccr.2009.09. 026

Zong, Y., Panikkar, A., Xu, J., Antoniou, A., Raynaud, P., Lemaigre, F., et al. (2009). Notch signaling controls liver development by regulating biliary differentiation. Development 136, 1727-1739. doi: 10.1242/dev.029 140

Conflict of Interest: The authors declare that the research was conducted in the absence of any commercial or financial relationships that could be construed as a potential conflict of interest.

Publisher's Note: All claims expressed in this article are solely those of the authors and do not necessarily represent those of their affiliated organizations, or those of the publisher, the editors and the reviewers. Any product that may be evaluated in this article, or claim that may be made by its manufacturer, is not guaranteed or endorsed by the publisher.

Copyright (c) 2021 Engel-Pizcueta and Pujades. This is an open-access article distributed under the terms of the Creative Commons Attribution License (CC BY). The use, distribution or reproduction in other forums is permitted, provided the original author(s) and the copyright owner(s) are credited and that the original publication in this journal is cited, in accordance with accepted academic practice. No use, distribution or reproduction is permitted which does not comply with these terms. 